François Templier Maidei Gugu Kabayadondo Frédéric Thys

\section{The use of the Boussignac CPAP device during cardiogenic pulmonary edema (CPE): why add air to the oxygen gas source?}

Accepted: 5 May 2011

Published online: 21 June 2011

(C) Copyright jointly held by Springer and ESICM 2011

An author's reply to this comment is available at: doi:

10.1007/s00134-011-2286-1.

Dear Editor,

We have read with great interest S. Nouira et al.'s [1] multicenter study comparing the use of CPAP and NIPSV in the management of cardiogenic pulmonary edema (CPE) in the emergency department (ED). Several similar studies on the topic have been performed in the ED [2]. Nouira et al.'s study has the advantages of having associated noninvasive ventilation (NIV) with the currently recommended medical treatment (nitrite bolus), and having used the Boussignac CPAP device (Vygon, 95440 ECOUEN France) in the CPAP group, a highly effective and user-friendly device [3]. The authors chose to adjust the air-tooxygen ratio to keep $\mathrm{SpO}_{2}$ above $90 \%$. For the Boussignac CPAP device, this was obtained by using an air-oxygen mixture as the gas generating the continuous pressure.

As previous studies have shown, the authors conclude that the two NIV techniques have similar effects on intubation rate and mortality reduction. However, NIPSV was associated with a shorter symptom resolution time compared to CPAP $(159 \pm 54$ vs. $210 \pm 73 \mathrm{~min} ; p<0.01)$. Resolution was defined as a respiratory rate $<30 \mathrm{~min}^{-1}$ and $\mathrm{SpO}_{2}>96 \%$ under $\mathrm{O}_{2}$ supplementation $<3 \mathrm{~L} / \mathrm{min}$ in the CPAP group or under $\mathrm{FiO}_{2}<35 \%$ in the NIPSV group.

We are surprised at the substantial amount of time necessary before symptomatic improvement with CPAP, as described by the authors. This resolution appears particularly long and does not correspond to our experience nor that of Moritz et al. in the use of Boussignac CPAP device, where patients' symptoms are generally improved in less than $1 \mathrm{~h}[3,4]$. The authors did not describe in detail what medical treatment the patients actually received. We could ask the question as to whether the medical treatment received was optimal. Another element that could explain this prolonged resolution time is having limited the $\mathrm{FiO}_{2}$ administered to patients. The authors chose to administer oxygen for an $\mathrm{SpO}_{2}$ of $90 \%$, without detailing the actual $\mathrm{FiO}_{2}$ delivered to the patients in both the CPAP and NIPSV groups. Yet $\mathrm{CPE}$ is principally a hypoxemic form of respiratory distress. The benefit of NIV is well-established and that of high concentration oxygen remains valid. Among the different free flow CPAP systems recommended, the advantage of the Boussignac CPAP device lies in allowing for the administration of oxygen at high $\mathrm{FiO}_{2}$ values yet with less consumption of oxygen than with CPAP devices using the Venturi system [5], without increasing the risk of hypercapnia [4]. Furthermore, the use of high concentration oxygen as the only gas source simplifies the use of the Boussignac CPAP device.

For the management of CPE in the ED, contrary to Nouira et al., we would recommend the use of the Boussignac CPAP device with oxygen as the only gas source. This not only simplifies the use of the device but could promote a more rapid resolution of symptoms.

\section{References}

1. Nouira S, Boukef R, Bouida W, Kerkeni W, Beltaief K, Boubaker H, Boudhib L, Grissa MH, Trimech MN, Boussarsar H, Methamem M, Marghli S, Ltaief M (2011) Non-invasive pressure support ventilation and CPAP in cardiogenic pulmonary edema: a multicenter randomized study in the emergency department. Intensive Care Med 37:249-256

2. Collins SP, Mielniczuk LM Whittingham HA, Boseley ME, Schramm DR, Storrow AB (2006) The use of noninvasive ventilation in emergency department patients with acute cardiogenic pulmonary edema: a systematic review. Ann Emerg Med 48:260-269

3. Templier F, Dolveck F, Baer M, Chauvin M, Fletcher D (2003) 'Boussignac' continuous positive airway pressure system: practical use in a prehospital medical care unit. Eur J Emerg Med 10:87-93

4. Moritz F, Brousse B, Gellée B, Chajara A, L'Her E, Hellot MF, Bénichou J (2007) Continuous positive airway pressure versus bilevel noninvasive ventilation in acute cardiogenic pulmonary edema: a randomized multicenter trail. Ann Emerg Med 50:666-675

5. Templier F, Dolveck F, Baer M, Chauvin M, Fletcher D (2003) Laboratory testing measurement of $\mathrm{FiO}_{2}$ delivered by Boussignac CPAP system with an input of $100 \%$ oxygen (in French). Ann Fr Anesth Reanim 22:103-107

F. Templier ( $)$ SAMU 92, SMUR Garches,

Raymond Poincaré Teaching Hospital, Assistance Publique - Hôpitaux de Paris, 104 boulevard Raymond Poincaré, 92380 Garches, France

e-mail: francois.templier@rpc.aphp.fr

Tel.: +33-1-47107001

Fax: 33-1-47107007

M. G. Kabayadondo - F. Thys

Emergency Department, Cliniques

Universitaires Saint-Luc,

Université Catholique de Louvain,

Avenue Hippocrate 10,

1200 Bruxelles, Belgium 